\title{
Cognitive Engagement in Online Intercultural Interactions: Beyond Analytics
}

\author{
Leni T. Casimiro
}

\begin{abstract}
The high drop out or attrition rate in many online classes as well as concerns on their quality have attracted research in online student engagement. Of particular importance among the dimensions of engagement is cognitive engagement because of its close affinity with learning. However, the distance factor between teachers and online students and the mental nature of cognitive processes make cognitive engagement difficult to observe. Academic analytics provide a picture of student engagement but learning is far from quantifiable. This paper attempts to explore the conditions that support cognitive engagement in online classes through discourse analysis of the discussion forum. Results showed five conditions that could have defined student engagement: nature of discussion questions, the mitigating factors for the level of student response, learning community, student characteristics, and teacher facilitation. Of these five, the nature of discussion questions, quality of student response, and learning community appeared to be the best to promote cognitive engagement.
\end{abstract}

Index Terms-Cognitive engagement, interculturality, learning community, online interaction, student engagement, discourse analysis.

\section{INTRODUCTION}

Student engagement has been a well-researched construct in mainstream education because of the need to improve student outcomes in schools. Many studies show that there is a "causal relationship between engaged time, that is, the period of time in which students are completely focused on and participating in the learning task, and academic achievement" [1]. They also found that students who are highly engaged in their classes have higher chances of completion and lower tendency to drop out of school [2].

The reported high dropout or attrition rate in online classes [3] as well as concerns on quality online instruction have likewise attracted research in online student engagement. Since online courses are usually designed in advance before delivery, teachers and instructional designers normally ask, how can I be sure that students will learn in this class? Two big words come to the fore: interactivity and engagement. That is, online students must interact not just with teachers but also with peers, content, and their environment [4]; and at the same time be fully engaged in the learning process. The two concepts are actually interrelated since interactivity is considered one of the conditions for engagement [5].

The distance factor between teachers and students in online education makes student engagement difficult to observe in this modality. This is complicated further when students come

Manuscript received September 15, 2014; revised December 18, 2014.

L. T. Casimiro is with the Adventist International Institute of Advanced Studies, Cavite, Philippines (e-mail: leni@aiias.edu). from varied cultural backgrounds, a common scenario in most online classes. Some evidences like interacting actively in online discussions may be used to gauge engagement; but what if the interaction is merely socialization? Strong connections with classmates may prevent the student from dropping out but it doesn't automatically translate to deeper thinking processes or cognitive engagement. On the other hand, a student may not be very active in the discussion forum but is actually actively processing the lesson mentally on his own and may even top the final exam. This is probably the reason why too few studies have been done on online student engagement.

One way of observing student engagement in online learning that has recently become popular is through academic analytics [6]. Learning management systems are now capable of tracking and storing vast amounts of data on student behavior, such as number of posts in the discussion forum, number of times a student accesses a resource or learning activity, and others. However, although these data can be used as indicators of engagement, they cannot fully represent learning and thus are merely called "proxies for actual learning" [7].

How then is student engagement in online learning best explained? More specifically, how can we determine the nature of cognitive engagement by online students in the learning process? What are the conditions that lead to deeper thinking processes in online courses? These are the questions this study aims to explore. This study attempts to contribute to the scanty research in online student engagement and at the same time supplement the limitations of learning analytics.

\section{LITERATURE REVIEW}

Two strong forces that have rekindled interest on student engagement in recent years are the need to improve school completion rates [8] and the changing demands of the global marketplace [9]. Research has proven that students who are engaged in school tend to achieve academically [10]-[12] The new global economy, likewise, call for students who must have been deeply and actively engaged in their learning because, among others, they are expected to be able to think critically and creatively, solve problems, reason effectively, communicate clearly, and collaborate with others [13].

In this review, engagement, as a construct, is then explored followed by a special focus on cognitive engagement. Two important conditions that may influence engagement that are present in the subject of this study are likewise briefly discussed: learning community and interculturality.

\section{A. Student Engagement}

Student engagement is the "quality of effort students 
themselves devote to educationally purposeful activities that contribute directly to desired outcomes" [14]. Other authors simply define engagement in terms of students' time-on-task, willingness to participate in activities, interest, effort, and motivation [15]. Researchers, however, agree that the construct is complex and is multifaceted in nature. Thus, the research literature looks at engagement in three ways [16].

Behavioral engagement draws on the idea of participation; it includes involvement in academic and social or extracurricular activities and is considered crucial for achieving positive academic outcomes and preventing dropping out. Emotional engagement encompasses positive and negative reactions to teachers, classmates, academics, and school and is presumed to create ties to an institution and influence willingness to do the work. Finally, cognitive engagement draws on the idea of investment; it incorporates thoughtfulness and willingness to exert the effort necessary to comprehend complex ideas and master difficult skills.

Davis et al. [17] also believe on the three-dimensional nature of engagement but contend that emotional engagement is actually referring to relational engagement because it encompasses the need for acceptance and belonging in the school.

\section{B. Engagement in Online Learning}

Engagement studies in online learning do not deviate from the foundational definitions of the construct. Researchers, however, recognize that the difficulties of measuring engagement in traditional classroom settings are even more magnified when done online [18]. Some difficulties that could inhibit engagement in online learning are procrastination, unpreparedness for self-directed learning, distance, lack of competency in the language used in the virtual class, etc. These underscore the importance of understanding how student engagement is achieved online and the accompanying difficulty of measuring it. To address these problems, researchers suggest ways to design online classes in order to ensure engagement. The following have been found, thus far: a) supportive learning communities [19]; b) engaging multimedia [20]; c) active online discussion forums [21], [22]; d) authentic learning activities [21], [22]; e) responsive student support system [22]; and f) effective instructional design [23].

\section{Cognitive Engagement}

Amidst all suggestions to engage online students, concerns are still aired as to the certainty of cognitive engagement in online classes. Some researchers found that a student may, for instance, be behaviorally engaged but not cognitively engaged. This is shown when a student works hard but still unable to achieve much [24]. Thus, others take the extreme stand that "for learning to be truly meaningful students have to be cognitively engaged" [25].

Of the three engagement types, it is cognitive engagement that is closest to learning as it involves the mental processes involved in class work. Cognitive engagement typically describe "the ways in which students think deeply about ideas and concepts, how they make meaning of the material presented to them, and how they use self-regulating and metacognitive strategies to master academic content and tasks" [26]. Thus, of the three dimensions of engagement, cognitive engagement is the most difficult to observe or measure and probably the most difficult to achieve.

Research in cognitive engagement reveals that this construct is best understood by looking into psychological investment by students, particularly goal orientation and intrinsic motivation, as well as learning strategies, particularly in the area of self-regulation, employed by them. Recognizing the weakness of cognitive engagement research, experts suggest that efforts must be focused on studying how students think and the use of observational techniques that assess the quality of engagement [27]. In the online environment, this is not reflected merely in counting how many times the student accesses the learning materials, posts in the discussion forums, or submits assignments, as learning analytics show. This is rather seen in a deeper evaluation of engagement during instruction in order to assist students in achieving desired learning outcomes.

\section{Learning Community}

One of the basic premises of successful online learning is the formation of learning community in the online class [28], [29]. Social relationships and connections tend to support cognitive engagement as it encourages discourse. Research has already established that a sense of belonging with teachers or successful peers can facilitate school achievement [30].

Interactivity in a learning community needs to be fostered in order to challenge students cognitively [31]. In today's classrooms, "the trend is to reduce the 'amount' of information delivered and to increase the 'interactive value' of the learning experience" [32]. Interactivity in online classes normally happens in the discussion area if done asynchronously, and chat rooms or videoconferencing rooms if done synchronously.

\section{E. Interculturality}

In today's online classrooms, it has become inevitable to see cultural differences with students coming from many countries, educational backgrounds, and mother tongues. While this can become a challenge in face-to-face interactions, it is much more so online [33]. Thus, to address this challenge, interculturality is to be practiced in the online classroom. Interculturality is defined as "the interaction of people from different cultural backgrounds using authentic language appropriately in a way that demonstrates knowledge and understanding of the cultures. It is the ability to experience the culture of another person and to be open minded, interested, and curious about that person and culture" [34]. The online teacher has a big role to play in modeling cultural sensitivity through class discussions as well as in designing instruction in a way that strengthens interculturality.

\section{Methodology}

This study used computer mediated discourse analysis [35] to examine the dynamics in online interactions, both by individual students and as a group. Since the focus of interest is cognitive engagement, the thinking processes involved in the responses by students were assessed vis-à-vis environmental conditions in the online class. The underlying 
assumption is that texts in the forum discussions can show evidence of what students know, think or feel.

To observe the full impact of distance in the online interactions, a fully online class was chosen for this study. The class was made up of 14 fully online graduate students who were taking a Master of Public Health course in one university. The students came from 8 countries in three continents-Asia, Africa, and America.

The first step was to look at the discussion questions posted by the teacher to determine their cognitive level in terms of Bloom's taxonomy of educational objectives [36]. Then students' responses were examined as to their quality or cognitive level and the possible factors that could have influenced their engagement. Two raters evaluated the questions and the responses posted by students in the online discussion forums.

\section{DISCUSSION OF FINDINGS}

Analysis of interactions in the discussion forums of the observed online class showed five areas that could have defined student engagement. These were the type of questions prepared by the teacher, the quality of students' response, the existence of a learning community, teacher's forum facilitation, and certain student characteristics.

\section{A. On Teacher's Discussion Questions}

All of the 20 main discussion questions that were prepared for the whole duration of the class were found to be in the higher level of the cognitive domain of Bloom's taxonomy. A few were testing mainly for understanding or comprehension of the content but $90 \%$ of the total called for application, analysis, synthesis, and evaluation skills of students. This is an example of the question posted by the teacher:

"Calcium, a bone mineral, is an important nutrient in bone health. Ecologic studies show that the incidence of hip fractures (an indicator of osteoporosis or another bone disease) is more prevalent in developed countries where calcium intake is higher than in developing countries. What do you think is/are the reasons for this paradox?"

In this question, the teacher not only expects students to analyze the paradox but also calls them to think globally. Eight of the 20 discussion questions were global in nature, hence students from different countries were equally motivated to participate in the discussion.

Along with the main discussion questions and during the discussion period, the teacher occasionally posted follow-up questions as well to further direct the students to essential related topics. These questions were also found to be in the application and above levels of Bloom's taxonomy. Thus, it can be said that the teacher in the observed class initiated cognitive engagement on the students.

\section{B. On Students' Responses}

There were a total of 1,488 responses on the questions from the 14 students. Hence, each of the main question posted by the teacher generated an average of 64 responses or an average of 106 posts per student, a proof that the students were generally motivated to participate in class discussions.
These responses were examined by classifying them according to the depth and breadth of contribution to the discussion. These ranged from a simple praise or agreement to a classmate's answer, or even merely asking further questions, to answers that varied according to the level of research and critical thinking involved. Obviously, answers that are based on personal opinion or experiences are considered less cognitively engaging compared to those that are research-based, particularly when critical thinking is exercised.

Initially, seven categories of responses emerged from the data, namely: praising, simply agreeing, asking question, connecting, extending, expanding, and emancipating. However, three of these-praising, simply agreeing, asking question-were later merged as one because of minor occurrence when treated singly and appeared to be in the same level of cognitive engagement. There were also those who simply were quiet but showed evidence of accessing the discussion. Hence, another category was added to account for those who did not post any answer, constituting the lowest level of engagement. As a result, the following six levels of cognitive engagement emerged from the data, as shown in Fig. 1:

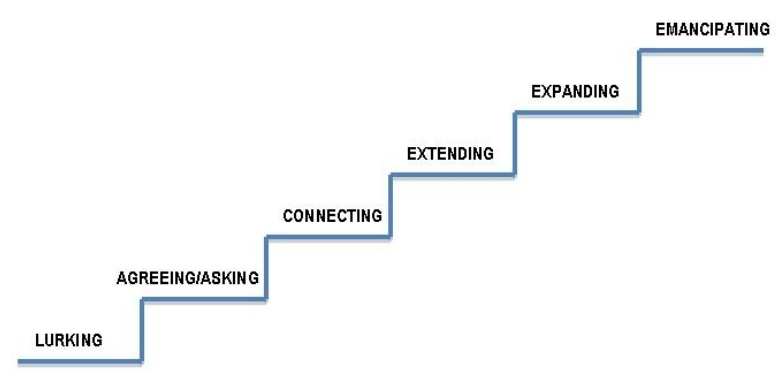

Levels of Cognitive Engagement

Fig. 1. Levels of cognitive engagement.

Below are the descriptions of each level:

1) Lurking or non-response - zero or probably minimal cognitive engagement. There may be personal engagement with the course content but no evidence is observable.

2) Praising/Simply agreeing - little cognitive engagement. Expressing simple agreement with a classmate's answer may indicate some thinking, particularly when it parallels one's ideas. However, simply agreeing may also mean mere acknowledgment of a good answer, a desire to connect with others, a cover-up of one's lack of understanding, or for one's presence to be felt in class. Hence, it doesn't always indicate clear understanding of the lesson.

3) Connecting - some cognitive engagement. The student attempts to respond but bases the answer purely on personal opinions or experiences and thus lacks scholarship.

4) Extending - The student responds to the question on the basis of research or scholarly evidence and shows interest by asking further questions or clarifications along the same line of argument.

5) Expanding - The student responds to the question by extending but also (a) adds fresh ideas to the discussion, 
(b) applies concepts learned to new situations, or (c) considers implications in other areas of the topic.

6) Emancipating - An evidence of mastery of the topic is shown by exercising critical thinking and making personal convictions on the issue at hand. At this stage, the student is able to engage in intellectual conflict, without fear of being judged badly or disliked by others. This is the highest level of cognitive engagement.

Using the above levels of cognitive engagement, individual results showed that majority of the students (12 of 14) in the class studied have reached the extending level while 9 of them were able to reach the expanding level in their posts. This only shows that the class has succeeded in engaging most of its students cognitively. However, when the total number of posts was considered (see Table I below), it appeared that the majority of students' posts $(40.39 \%)$ were in the connecting level or contained mere opinions or personal experiences. This shows that although students consider relevant sources in their answers, they cannot avoid posting their opinions and personal experiences related to the topic. It was apparent from every discussion that the class members were actively sharing experiences that were unique in their respective cultures. The students seemed to feel comfortable in being "open" and highly interactive — an evidence of a strong learning community in the class [37].

TABLE I: STUDENT POSTS By LEVEL OF ENGAGEMENT

\begin{tabular}{|c|c|c|}
\hline Level of Engagement & $\begin{array}{c}\text { Number of Posts } \\
n=1488\end{array}$ & $\%$ \\
\hline Lurking & 20 & 1.34 \\
\hline $\begin{array}{c}\text { Praising/Simply agreeing or } \\
\text { asking }\end{array}$ & 38 & 2.55 \\
\hline $\begin{array}{c}\text { Connecting } \\
\text { Extending }\end{array}$ & 601 & 40.39 \\
\hline Expanding & 413 & 27.76 \\
\hline Emancipating & 329 & 5.85 \\
\hline
\end{tabular}

An initial observation of the overall online discussion brings one to recognize the value of good questions prepared by the teacher. Indeed, as the literature has already documented, critical thinking questions can generate high-level answers from students. But since not all answers were high level, what could have caused the difference between the highly engaged students and those that were weakly engaged? Why do some students lurk, others bluff, while others are active? This necessitated an individualized examination of participation by the students.

Individual observations not only looked into the quality of student posts but also in their participation patterns, particularly in terms of the number and timing of their posts and their characteristics. Academic analytics afforded by learning management systems can easily show the number of hits and the number of forum posts by individual students. Data mining revealed a wide discrepancy in the participation rate of students, despite the seeming active appearance of the whole class. The number of posts by individual students in one discussion question alone (Forum 5), for example, ranged from 0 to 30 posts. This means the class appeared to be dominated by some students while others lurked. The goal of every educator is of course active participation by all; so this can be a concern. On further examination of the discussion forum, these were the observations:

1) Although the discussion questions were high in terms of cognitive level, in many instances they called for specific answers because of the scientific nature of the subject matter. For example, one question states When planning a community project, why is it important to do needs assessment? This calls for an explanation but cursory examination of the class lecture reveals a good discussion of this topic already. Hence, once the first response gives a complete answer, other students were forced to simply agree or praise the responder (for example, "I couldn't agree more ___. Thank you."), indicating a low level of cognitive engagement. There appeared to be a race in class on who can post the first response.

2) Despite some specificity in the answers to many questions, students were still active in sharing their personal ideas because of the felt relevance of the topics. The class topic - nutrition - appeared to have attracted the interest of the students. As an example of the students' excitement on the class, one post in the Introductions forum stated "I am very excited to learn about public nutrition with some disturbing facts in my mind such as my country India is home to more than $40 \%$ of malnourished children in the world and in my current country of residence, Malawi $46 \%$ of the under 5 children are malnourished and is the biggest cause for increased infant mortality rate. I am confident . . ." Another student posted "I am looking forward to this class. Nutrition has been a topic that I have been very interested in for many years. I have been especially interested in how nutrition affects chronic diseases. I am also very interested in the discussions on the use of supplements..."

3) It appears that students who tended to lurk or had few posts were the late responders. Nevertheless, some of them are still able to post high cognitive level answers. A report by the student services coordinator who was assisting the students revealed that these students were either "too busy with work" or "had personal issues" that prevented them from active participation. One even said, “. . . as long as I answered the question, I think that's enough" (email communication).

Further examination of student interactions revealed other observations. These were related to the existence of learning community and student characteristics, which are discussed below.

\section{On Learning Community}

Learning community, obviously, has already been established prior to the beginning of the class. The Introductions forum alone has generated 86 posts as students welcomed both old and new classmates. Old students recalled experiences in past classes while new students were assured of an exciting learning journey together. This contributed to 
the comfort level experienced by students to participate. This kind of post is commonly mentioned "Hi Mary. Nice to be sharing the same class with you again. I appreciate your very informative and honest insights and sharing from our previous class. Looking forward to our future interactions here. God bless!"

It was, however, observable, that the students in the class almost did not disagree with each other even in some controversial issues. Are they supposed to be comfortable even to disagree with each other because of the learning community they already formed? Examined as to why intellectual conflict seemed stifled even though there appeared to be strong community in the class, it was found that friends in class showed inhibitions in engaging in conflicting exchange of ideas or critical discourse for fear of hurting others. They either resorted to silence or immediately feeling sorry for expressing an opposite viewpoint. For instance, one student who happened to be a newcomer and hence would not have yet developed a strong connection with the class community was frank enough to strongly disagree with one old member of the group: "Wow! I am not sure I agree with the way you characterize people as lazy ..." Then the old student immediately apologized, “. . . I do apologize if I seem to make absolute statements. I do mostly mean them to be general ...." Then another old classmate was ready to stand at his defense, "Maybe John is not literally saying we are lazy, it means we are made lazy with the available technology in our midst." Then the discussion stopped.

\section{On Student Characteristics}

One area that this research tried to look at was the role of a student's cultural background in online interactions. The students in the class came from 8 countries in three continents: Asia, Africa, and America. As mentioned earlier, since the teacher tried to incorporate global thinking in the questions for discussion, students showed excitement and comfort in sharing their experiences in their own countries, whether it is positive or negative. Interculturality was evident among the students. However, from the analytics, it appears that Asians were generally the most talkative or participative at an average of 125 posts per head, with the Americans following closely at 117 posts per head, and the Africans showing least participation at 54 posts per head. The literature normally pictures Asians as less talkative in online interactions compared to Americans because of language differential [38]. However, a cursory examination of the Asian students in this class showed that, except for two, all the rest were working outside their country of origin and hence may have acquired new cultures. The African students happened to be the busy ones in their workplaces hence their lack of participation may not have always been due to culture.

This study also looked into gender and online learning experience of the students to determine if females, for example, are more participative than males or if older students are more interactive than new ones. From the analytics, it appears that both male and female students were equally active. In fact, the top four most active students in the online discussions consisted of two males and two females. As to their online learning experience, it appears that new students may not be the top participants of the class but they were not far behind. This is probably because of the warm welcoming learning community of the class that made them comfortable right away.

\section{E. On Teacher's Facilitation}

The teacher's posts, other than the main discussion questions, were likewise examined to determine their impact on student participation. Data from analytics revealed 142 posts by the teacher compared to 1,488 posts by students. As to the quality of the teacher's responses, around $10 \%$ are in the praising or simply agreeing level. This result clearly shows that the teacher's interaction during discussions was moderately inactive and may not have impacted the response by students. Other factors could have been powerful enough to motivate the students to participate actively in class.

\section{CONCLUSION}

Based on the analysis of online interactions, cognitive engagement can be achieved in online classes through the discussion forum. Certain conditions, however, need to exist in class. The discussion questions need to be carefully prepared in ways that require higher levels of thinking as well as critical thinking. Depending on the question asked, the quality of student response can vary widely from mere lurking or simply agreeing to connecting and on to higher levels by giving extending or expanding answers, and even emancipating themselves by making personal convictions.

Deep and interactive discussions, however, do not result automatically from high-level questions. It is not difficult to find online classes where students merely respond to teacher's posted questions and rarely interact with classmates. As can be observed from the discourse analysis in this study, while most of the students reached high levels of cognitive engagement, there was a higher percentage of interaction in the 'connecting' level. This only shows a possible link between student connectedness or learning community and cognitive engagement. Other researchers [39], [40] have also found that active participation or socialization supports discourse, which in turn leads to knowledge construction among students. The existence of a strong learning community in the observed class, indeed, contributed to a comfortable learning environment such that even if the teacher was not very active in interacting with them, the discussion continued freely.

One thing that generated active discourse in this study were questions that are relevant to students' needs, those that accommodate cultural realities in a global scale, and those that ask for personal stand on related issues. While such questions may call for personal experiences or perceptions, they may lead to critical evaluation of their beliefs based on theories learned in class. Again, this must be made intentional in the way questions are asked so as to engage students in higher levels of thinking.

One interesting finding of this study is that a strong learning community is supportive of discourse only up to a certain extent. When intellectual conflicts occur, online students tend to shy away from engaging in continued critical discourse, 
probably in order to preserve good relationships among them. Another interesting finding is that the number and timing of posts may not always relate to the quality of students' response. This makes careless judgments based on analytics dangerous. Lurking among students may be due to personal busyness and may not mean lack of understanding. Should they be punished for posting responses minimally?

It was not clear in the interactions if culture or gender is still an issue in an intercultural online classes. What were evident were the intentional inclusion of global perspective in the discussion questions and the possible avoidance of conflict due to collectivist nature of the majority of the students' culture. It was not clear also if class size or other aspects of the course like course structure and instructional design contributed to successful interactions even though teacher presence was lacking. These could be the subjects of further research.

\section{REFERENCES}

[1] M. Bulger, R. Mayer, K. Almeroth, and S. Blau, "Measuring learner engagement in computer-equipped college classrooms," Journal of Educational Multimedia and Hypermedia, vol. 17, no. 2, pp. 129-143, April 2008.

[2] J. Fredricks, P. Blumenfeld, and A. Paris, "School engagement: Potential of the concept, state of the evidence," Review of Educational Research, vol. 74, no. 1, pp. 71-73, Spring 2004.

[3] B. Burnsed. (October 20, 2010). Curtailing dropouts at online universities. US News. [Online]. Available: http://www.usnews.com/education/online-education/articles/2010/10/ 20/curtailing-dropouts-at-online-universities.

[4] T. Anderson, The Theory and Practice of Online eLearning, Canada: Athabasca University Press, 2008, p. 32.

[5] B. Sarder, "Improving student engagement in online courses," presented at the $121^{\mathrm{st}}$ ASEE Annual Conference and Exposition, Indianapolis, IN, June 15-18, 2014.

[6] J. P. Campbell, P. B. DeBlois, and D. G. Oblinger, "Academic analytics: A new tool for a new era," Educause Review, pp. 41-57, July/August 2007.

[7] C. Beer, K. Clark, and D. Jones, "Indicators of engagement," in Proc. Ascilite Sydney 2010: Curriculum, Technology \& Transformation for an Unknown Future, C. H. Steel, M. J. Keppell, P. Gerbic, and S. Housego, Eds., p. 78, 2010.

[8] M. Lawson and H. Lawson, "New conceptual frameworks for student engagement research, policy, and practice," Review of Educational Research, vol. 83, no. 3, pp. 432-433, 2013.

[9] V. Mansilla and A. Jackson, Educating for Global Competence: Preparing Our Youth to Engage the World, New York, NY: Council of Chief State School Officers' EdSteps Initiative \& Asia Society Partnership for Global Learning, 2011, pp. 1-2.

[10] M. Bulger, R. Mayer, K. Almeroth, and S. Blau, "Measuring learner engagement in computer-equipped college classrooms," Journal of Educational Multimedia and Hypermedia, vol. 17, no. 2, pp. 129-143, April 2008.

[11] M. Lawson and H. Lawson, "New conceptual frameworks for student engagement research, policy, and practice," Review of Educational Research, vol. 83, no. 3, p. 436, 2013.

[12] J. Fredricks, P. Blumenfeld, and A. Paris, "School engagement: Potential of the concept, state of the evidence," Review of Educational Research, vol. 74, no. 1, pp. 63-65, Spring 2004.

[13] Partnership for $21^{\text {st }}$ Century Skills. (December 2009). $21^{\text {st }}$ Century Student Outcomes. [Online]. pp. 2-7. Available: http://www.p21.org/storage/documents/P21_Framework_Definitions. pdf

[14] K. Krause and H. Coates, "Indicators of engagement," in Proc. Ascilite Sydney 2010: Curriculum, Technology \& Transformation for an Unknown Future, C. H. Steel, M. J. Keppell, P. Gerbic, and S. Housego, Eds., p. 76, 2010.

[15] C. Beer, K. Clark, and D. Jones, "Indicators of engagement," in Proc. Ascilite Sydney 2010: Curriculum, Technology \& Transformation for an Unknown Future, C. H. Steel, M. J. Keppell, P. Gerbic, and S. Housego, Eds., p. 76, 2010.
[16] J. Fredricks, P. Blumenfeld, and A. Paris, "School engagement: Potential of the concept, state of the evidence," Review of Educational Research, vol. 74, no. 1, p. 60, Spring 2004.

[17] H. Davis, J. Summers, and L. Miller, An Interpersonal Approach to Classroom Management: Strategies for Improving Student Engagement, Thousand Oaks, CA: Sage Publications, 2012, pp 23-25.

[18] I. Douglas and N. Alemanne, "Indicators of engagement," in Proc. Ascilite Sydney 2010: Curriculum, Technology \& Transformation for an Unknown Future, C. H. Steel, M. J. Keppell, P. Gerbic, and S. Housego, Eds., pp.76-77, 2010.

[19] R. Palloff and K. Palloff, Building Learning Communities in Cyberspace, San Francisco: Jossey-Bass, 1999, pp. 17-20.

[20] S. Stoney and R. Oliver. (October 1999). Can Higher Order Thinking and Cognitive Engagement Be Enhanced with Multimedia? Interactive Multimedia Electronic Journal of Computer-Enhanced Learning. $\quad$ [Online]. 1(2). Available: http://imej.wfu.edu/articles/1999/2/07/

[21] Y. Levy, "An empirical development of critical value factors (CVF) of online learning activities: An application of activity theory and cognitive value theory," Computers \& Education, vol. 51, no. 4, pp. 1664-1675, December 2008.

[22] L. Casimiro, "Effective online instructional design as perceived by teachers and students in selected private colleges and universities," $\mathrm{PhD}$ dissertation, Education Department, Adventist International Institute of Advanced Studies, Cavite, Philippines, 2009.

[23] M. Hricko, "Student retention in distance education," in Motivating and Retaining Adult Learners Online, V. Phillips, Ed., Vermont, USA: GetEducated.com, LLC, 2002, ch. 1, pp. 3-10.

[24] H. Davis, J. Summers, and L. Miller, An Interpersonal Approach to Classroom Management: Strategies for Improving Student Engagement, Thousand Oaks, CA: Sage Publications, 2012, p. 23.

[25] A. Solis. (April 2008). Teaching for cognitive engagement: Materializing the promise of sheltered instruction. Intercultural Development Research Association. IDRA Newsletter. [Online] Available: http://www.idra.org/IDRA_Newsletter/April_2008_Student_Engage ment/Teaching_for_Cognitive_Engagement/

[26] M. Lawson and H. Lawson, "New conceptual frameworks for student engagement research, policy, and practice," Review of Educational Research, vol. 83, no. 3, p. 436, 2013.

[27] J. Fredricks, P. Blumenfeld, and A. Paris, "School engagement: Potential of the concept, state of the evidence," Review of Educational Research, vol. 74, no. 1, pp. 67-69, Spring 2004.

[28] R. Palloff and K. Palloff, Building Learning Communities in Cyberspace, San Francisco: Jossey-Bass, 1999, pp. 17-20.

[29] D. R. Garrison and T. Anderson, E-Learning in the $21^{\text {st }}$ Century, London: RoutledgeFalmer, 2003, ch. 1.

[30] H. Davis, J. Summers, and L. Miller, An Interpersonal Approach to Classroom Management: Strategies for Improving Student Engagement, Thousand Oaks, CA: Sage Publications, 2012, p. 24.

[31] R. Bernard, P. Abrami, E. Borokhovski, C. Wade, R. Tamim, M. Surkes, and E. Bethel, "A meta-analysis of three types of interaction treatments in distance education," Review of Educational Research, vol. 79 , no. 3, p. $1264,2009$.

[32] M. Simonson, S. Smaldino, M. Albright, and S. Zvacek, Teaching and Learning at a Distance, Boston, MA: Allyn \& Bacon, p. 157, 2012.

[33] R. Mason, "Global education: Out of the ivory tower (chapter 50)," Handbook of Distance Education, Mahwah, NJ: Lawrence Erlbaum Associates, pp. 743-753, 2003.

[34] F. Rollings-Carter, Module 5: The Importance of Interculturality, University of North Carolina School of Education, 2010.

[35] S. Herring, "Computer-mediated discourse analysis: An approach to researching online behavior," in Designing for Virtual Communities in the Service of Learning, S. Barab, R. Kling, and J. Gray, Eds., NY: Cambridge University Press, 2004, pp. 338-376.

[36] L. W. Anderson et al., A Taxonomy for Learning, Teaching, and Assessing: A Revision of Bloom's Taxonomy of Educational Objectives, New York: Pearson, Allyn \& Bacon, 2001, p. 6.

[37] D. R. Garrison and T. Anderson, E-Learning in the $21^{\text {st }}$ Century, London: RoutledgeFalmer, 2003, p. 25.

[38] G. Bingham and L. Okagaki, "Ethnicity and student engagement," in Handbook of Research on Student Engagement, S. Christenson, A. Reschly, and C. Wylie, Eds., NY: Springer, 2012, pp. 56-96.

[39] D. R. Garrison and T. Anderson, E-Learning in the $21^{\text {st }}$ Century, London: RoutledgeFalmer, 2003, p. 22

[40] G. Salmon, E-Moderating: The Key to Teaching and Learning Online, 3rd ed., London: Routledge, 2004, pp. 201-202. 


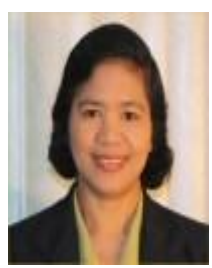

Leni T. Casimiro was graduated with a $\mathrm{PhD}$ in education, emphasis in curriculum and instruction, in 2009 from Adventist International Institute of Advanced Studies (AIIAS), in Cavite, Philippines. Currently, she is the director of AIIAS Online, the institution's virtual campus, which offers graduate level degrees in business, education, public health, and theology. She is also an associate professor in the Education Department of the Graduate School of the same institution. She specializes in online learning, curriculum, instructional strategies, instructional media, and inclusive instruction.
Dr. Casimiro has published research articles in journals and presented in various international conferences in Asia, Europe, and Canada, primarily on topics related to online learning. Her research interests include instructiona design, student engagement, interculturality, learning analytics, instructional technology, and integration of faith in distance learning. She is also a peer reviewer in some research journals. 